\title{
Pharmacological Management of Neuropathic Pain: Current Trends and Possible Approaches
}

\author{
Anil Kumar,, ${ }^{1,}$ Raghavender Pottabathini, ${ }^{1}$ Archana Bhatnagar, ${ }^{2}$ Sukant Garg, ${ }^{3}$ and Varun Gupta \\ ${ }^{1}$ Pharmacology Division, University Institute of Pharmaceutical Sciences, UGC Centre of Advanced Study, Panjab University, Chandigarh, India \\ ${ }^{2}$ Department of Biochemistry, Panjab University, Chandigarh, India \\ ${ }^{3}$ Department of Pathology, Dr. Harvansh Singh Judge Institute of Dental Sciences and Hospital, Panjab University, Chandigarh, India \\ "Corresponding author: Anil Kumar, Pharmacology Division, University Institute of Pharmaceutical Sciences, UGC Centre of Advanced Study, Panjab University, Chandigarh, \\ India. Tel: +91-1722534106, Fax: +91-1722543101, E-mail: kumaruips@yahoo.com
}

Received 2015 April 11; Revised 2016 July 06; Accepted 2016 August 01.

\begin{abstract}
Context: Neuropathic pain (NP) is a chronic debilitating painful condition with complex pathophysiology and inadequate treatment. Conventional pharmacological approaches and currently available drugs only provide marginal pain relief and cause significant adverse effects. The present manuscript is an attempt to summarize the existing data and possible pharmacological approaches available for NP.

Evidence Acquisition: Information was collected from Google Scholar, Cochrane and PubMed databases, Scopus and directory of open access journals. Neuropathic pain, chronic pain, diabetic neuropathy, pathophysiology and current recommendations were the terms used to search the literature. Data from relevant animal and randomized controlled studies were selected to get the up to date information of the currently available pharmacological approaches. A note on future approaches was added based on the recent animal and human studies.

Results: The current review made a significant attempt to focus on the mode of action, required dosage, advantages and the side effect profiles of currently available drugs used, or in investigational phases and their possible combinations to manage NP. Efforts are made to cover arise of NP because of diabetes and its management. At the end, authors made an attempt to cover the various therapeutic options that are currently explored for future drug development.

Conclusions: The available pharmacological approaches are effective on one or other types of chronic pain. But the inadequate pain relief and limitations with each class of drugs raises the need to develop better therapeutic approaches and also understand the pathology better. The present review may be helpful to researchers intending to focus on newer therapeutic strategies and targets to manage NP.
\end{abstract}

Keywords: Chronic Pain, Antidepressants, Anti-Epileptics, Opioids, Therapeutic Management

\section{Context}

Neuropathic pain (NP) is a severe debilitating form of pain which originates as a consequence of lesion or disease pertaining to somatosensory system. The term lesion refers to the actual/potential damage of neurons identified via laboratory diagnostic procedure, whereas the term disease refers to the known cause for the lesion. NP is a clinical description which helps to identify the possible underlying causes. Etiology of NP ranges from traumatic nerve damage/compression, diabetes, cancer and its chemotherapy, viral infections such as HIV, alcohol and other toxin exposure, surgical amputations, etc. Furthermore, pain originated from a lesion or disease in central or peripheral somatosensory nervous system leads to the categorization of NP into central NP or peripheral NP, respectively. NP is associated with a wide range of sensory changes as described in Table 1(1). Currently available drugs provide only marginal pain relief and are associated with various adverse effects.
Therefore, understanding the current knowledge about complex pathology of NP and available drugs helps the researchers to rationalize the therapeutic approaches. This also aids in synthesizing the drugs, which can act on novel targets and exert effective pain relief with minimal side effect profiles. Hence, the pros and cons of different categories of available drugs were listed and also the possible targets that can be explored were highlighted.

\section{Evidence Acquisition}

Google scholar, Cochrane and PubMed databases, Scopus and directory of open access journal were searched for the literature with the terms: NP, chronic pain, diabetic neuropathy, pathophysiology and the current recommendations. Epidemiology of chronic pains, in particular NP, was discussed. Relevant animal and randomized controlled studies were searched to get the latest knowledge of the mechanisms involved in NPand currently avail- 
Table 1. Different Symptoms Associated with Neuropathic Pain

\begin{tabular}{|ll}
\hline & Symptoms \\
\hline Allodynia & Pain due to non-noxious stimuli (mechanical, dynamic and thermal) \\
\hline Anesthesia & Loss of normal sensation to the affected region \\
\hline Dysesthesia & Spontaneous or evoked unpleasant abnormal sensations \\
\hline Hyperalgesia & Exaggerated response to a mildly noxious stimulus \\
\hline Hyperpathia & Delayed and explosive response especially to a repetitive stimuli \\
\hline Hypoesthesia & Reduction of normal sensations to the affected region \\
\hline Paresthesia & Non painful spontaneous abnormal sensations to a stimulus that is not unpleasant \\
\hline Phantom pain & Pain arising from an amputated part \\
\hline
\end{tabular}

able pharmacological approaches. Different dosage recommendations and main side effects associated with them were also addressed. A note on future approaches was added based on recent animal and human studies.

\section{Results}

\subsection{Epidemiology}

Prevalence of NP is about 6.9\% (lasting for three months) mainly in middle-aged patients (50 - 64 years) $(2,3)$. Incidence rates of NP originating from associated disease or condition in general populations were 3.9 42.0/10000 person-years (PY) for postherpetic neuralgia (PHN), 12.6 - 28.9/10000 PY for trigeminal neuralgia, 15.3 72.3/100000 PY for painful diabetic peripheral neuropathy and 0.2 - 0.4/100000 PY for glossopharyngeal neuralgia (4). Attempts to develop a more rational therapeutic approach to manage NP are still challenging and are generally refractory to conventional analgesics such as nonsteroidal anti-inflammatory drugs (NSAIDs). The main reason of this lacuna is complex mechanisms (both peripheral and central) involved in the development of NP (5). Furthermore, the currently available drugs are not directed towards the multiple aspects of chronic pain.

\subsection{Available Data on Mechanisms and Pharmacological Man- agement of NP}

$\mathrm{NP}$ is associated with both negative and positive symptoms. Negative symptoms are due to impaired conduction in afferent sensory neurons leading to numbness and imparted conduction in efferent nerve fibers leading to muscle deficits (6). Positive symptoms are paresthesia, hyperesthesia and dysesthesia affecting significant populations worldwide. Increased sodium channel expression in dorsal root ganglion (DRG) sensory neurons and the site of injuries leads to ectopic activity in damaged neurons; secondary to decrease in threshold for action potential generation. Nerve injury increases noradrenergic sensitivity secondary to sensory sympathetic coupling generally relived by sympatholytic procedures. But this is accompanied by recurrence of pain, paresthesias after six months.

Loss of central terminal C fibers (transmit nociceptive information under normal physiological conditions) in dorsal horn lamina II because of nerve injury (a cause of negative symptoms) and sprouting of $\mathrm{A} \beta$ fibers (transmit innocuous information under normal physiological conditions) from lamina III and IV to lamina II lead to the development of touch evoked pain characteristic of PHN (7). This, along with lowered threshold of peripheral nociceptors, leads to enhanced functioning of second order neurons through the release of neuropeptides and excitatory neurotransmitters such as glutamate from primary afferents. The released neuropeptides and neurotransmitters act in their respective receptors on post synaptic neurons and initiate secondary events such as protein phosphorylation and nitric oxide release leading to central sensitization (8). Under normal physiological settings, this central sensitization is under the control of local inhibitory interneurons of gamma-aminobutyric acid (GABA) and glycine (Figure 1). Nerve injury leads to loss of this local inhibitory control causing potent allodynia (9). Therefore, agents that restore the GABA mediated inhibitory control can be a promising approach in the therapy of NP.

Supraspinally rostral ventral medulla has both inhibitory and excitatory control over dorsal horn neurons, but it is the facilitation of excitatory descending pathways that has a major role in the maintenance of NP. Studies showed that neuropeptide cholecystokinin (CCK) has a key role in this tonic descending facilitation of pain processing (10). Recently, enhancement of opioid induced antinociception in NP with CCK antagonists is shown in preclinical models. These agents simultaneously target CCK and opioid receptors $(\delta$ and $\mu$ ) (11). On the whole, nerve injury induces a variety of pathophysiological changes in the nervous system in response to a variety of insults. These changes often preclude the normal therapeutic options available in the treatment or sometimes make them totally nonresponsive. At the same time, these changes open 


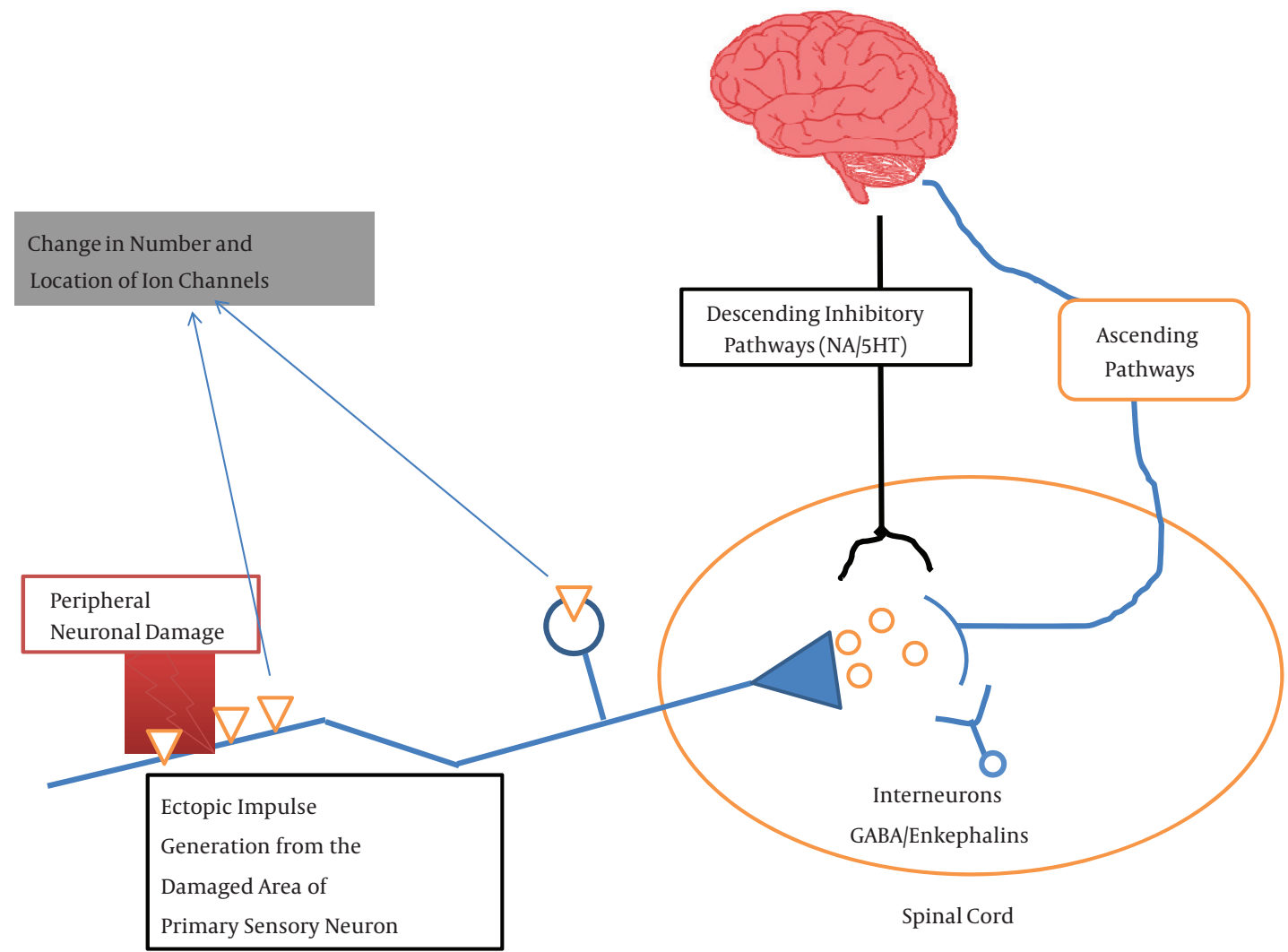

Figure 1. Simplified Diagram Showing the Nociceptive Pathways with the Possible Targets for Neuropathic Pain Treatment

up new targets. Above all, changes also occur in nonneuronal cells such as glial cells which upon activation release several inflammatory mediators via activation of immune components leading to neuroplastic changes (12).

Special emphasis is given to the peripheral diabetic neuropathy (PDN), since the prevalence is increasing day by day among patients with diabetes (4). Apart from hyperglycemia, classical metabolic pathways such as increase in polyol, hexosamine, advanced glycation end products, activation of protein kinase $C$ and poly-ARP are studied in progression of PDN. All these pathways ultimately converge to increase oxidative stress by increasing the production of reactive oxygen species. It conversely increases the inflammatory process leading to neuronal damage. Agents with alteration at one or other steps show promising results in preclinical and clinical studies. A brief discussion of this category is provided at the end. Furthermore, reactivation of dormant varicella-zoster virus in spinal and cranial sensory ganglia, where it exists in latent state postinfection with chickenpox results in sensory root, changes, sometimes leading to complete loss of small and large diameter sensory fibers (13). These changes lead to sponta- neous discharges, lowered threshold for action potential generation ultimately resulting into allodynia. Many of the patients with PHN also experience spontaneous burning pain (14).

\subsection{Current Recommendations}

Evidence based guidelines for the pharmacological management of NP was developed by international association for the study of pain which is also endorsed by the American pain society, European federation of neurological societies (EFNS), the Canadian pain society and the Mexican pain society. According to these guidelines, the first line agents include tricyclic antidepressants (TCAs), Ca channel alpha 2-delta ligands, selective serotonin/norepinephrine reuptake inhibitors (SNRIs) and topical lidocaine. Second line agents include opioids and tramadol. Revised guidelines of EFNS in 2010 recommendations are given in Box 1 .

\subsubsection{Antidepressants}

Studies show that antidepressants can exert their analgesic action without any effects on mood in patients with 


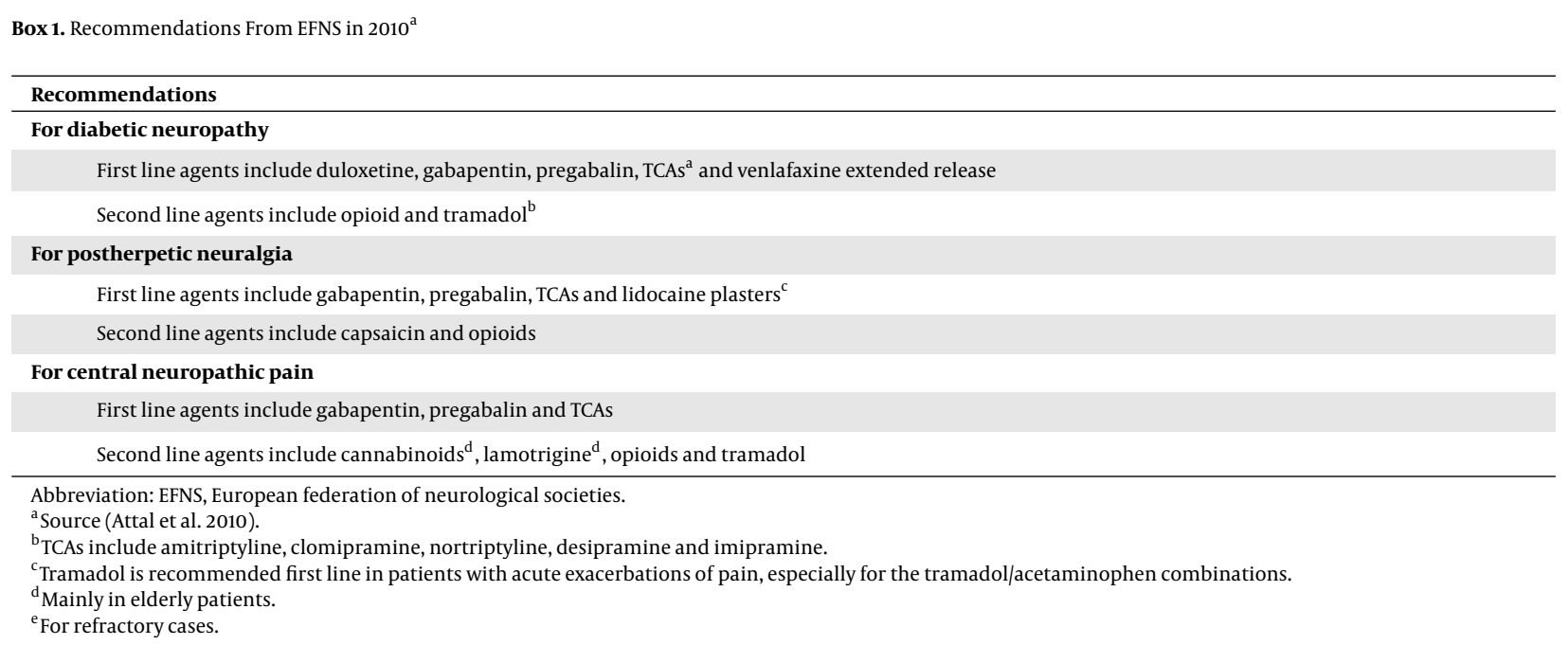

chronic pain, with or without concomitant depression (15). Furthermore, lower dose and shorter delay are required to achieve optimal analgesic action than that of required to achieve antidepressant action (16). This is mainly because of enhancement of descending monoaminergic inhibitory pathways via central blockade of serotonin and noradrenalin reuptake process. Apart from it, their effects on alpha-adrenergic, histaminergic (H1), muscarinic cholinergic receptor, N-methyl-D-aspartate (NMDA) antagonistic effects and blockage of sodium (17) and voltage gated calcium channel (18) are also reported (19). This category mainly consists of tricyclic antidepressants (TCAs), selective serotonin reuptake inhibitors (SSRI) and serotoninnorepinephrine reuptake inhibitors (SNRIs).

Tricyclic antidepressants: TCAs consisting of tertiary amines amitriptyline, imipramine, trimipramine, clomipramine, doxepin and their demethylated secondary amines nortriptyline, desipramine, protriptyline, amoxapine are studied to treat NP. TCAs showed positive results to treat PDN, PHN, painful polyneuropathy and post mastectomy pain. However, there are studies showing negative results with TCAs in neuropathies caused by HIV (20), cancer (21) and chronic lumbar root pain (22). According to a Cochrane review, the number needed to treat (NNTs) remained approximately three for both TCAs and venlafaxine. It indicates that one out of three patients with NP who had taken either of these drugs, get at least moderate pain relief (23). This measure unit is used for retrospective evaluation of a drug's analgesic efficacy and shows the number of patients that need to be treated to produce greater than $50 \%$ pain relief. Patients receiving TCAs were significantly more likely to report at least $30 \%$ pain reduction.
By inhibiting the reuptake process, TCAs enhance the biogenic amines mediated descending inhibitory mechanisms of nociception (24). Unfortunately, TCAs also block histaminic, cholinergic, and alpha 1-adrenergic receptor sites, accounting for their unwanted side effects. More selective TCAs such as imipramine and nortriptyline cause fewer anticholinergic effects and less sedation. The most common anticholinergic side effects include dry mouth, constipation, sweating, dizziness, blurred vision, drowsiness, palpitation, orthostatic hypotension, sedation and urinary retention. TCAs can also cause cognitive disorders or confusion, gait disturbance and falls, particularly in elderly patients. Therefore, they should be used cautiously in patients at risk for suicide or accidental death from overdose (25) and avoided in patients who have ischemic heart disease or increased risk of sudden cardiac death.

Secondary amine TCAs (nortriptyline and desipramine) are preferred because of their better tolerability than tertiary amine TCAs (amitriptyline and imipramine) but have comparable analgesic efficacy (26, 27). Nortriptyline has similar analgesic activity with less sedation and orthostatic hypotension and is recommended for first line therapy (25).

\subsubsection{Selective Serotonin Reuptake Inhibitors}

There is only limited evidence available to suggest that SSRIs have protective pain-relieving effects on patients with peripheral NP (28). Currently available data suggest that SSRIs are clearly less effective than TCAs (NNT: 6.7 vs 2.4$)$ to manage NP $(29,30)$. Studies in rodents suggest that simultaneous inhibition of 5-hydroxytryptamine (HT) and NA reuptake appears to present a greater degree of antinociception than single mechanism of action in- 
hibitors (31). Furthermore, in various randomized controlled trials (RCTs) conducted using sustained release formulation of bupropion, it is shown that the additional reuptake of dopamine may further augment 5-HT/NA reuptake mediated antinociception after nerve injury $(32,33)$.

\subsubsection{Serotonin-Norepinephrine Reuptake Inhibitors}

Drugs capable of inhibiting both serotoninnorepinephrine reuptake pumps are effective on various types of NP $(34,35)$. Duloxetine has attracted more attention in this class. It is the first line drug, approved by US food and drug administration (USFDA), to treat the patients with PDN, fibromyalgia, musculoskeletal back pain and osteoarthritis. Both 60 and $120 \mathrm{mg} /$ day of duloxetine are effective over placebo in various RCTs (16, $35,36)$. Recently, in a multicenter RCT, five week treatment with duloxetine resulted in greater decrease in pain in patients with painful chemotherapy induced peripheral neuropathy (37). Moreover, it was devoid of anticholinergic and cardiac side effects. NNT for duloxetine was 6.4 (38). Starting dose should be $30 \mathrm{mg} /$ day to avoid nausea and titrated after one week to $60 \mathrm{mg} /$ day.

Mianserin, a SNRI, and its analogue mirtazapine potentiate the analgesic action of various antinociceptive drugs in animals but failed to show their analgesic action in humans. In a small randomized crossover study, including patients with PDN, mianserin failed to show any protective effects (39). Presently, mirtazepine is studied in fibromyalgia and chronic pain (40). It has an agonistic action at 5$\mathrm{HT}_{1 \mathrm{~A}}$ receptors and an antagonistic action at $\alpha 2$-adrenergic and $5-\mathrm{HT}_{2}, 5-\mathrm{HT}_{3}$ serotonergic receptors.

\subsubsection{Venlafaxine}

Venlafaxine is another compound of this class which behaves like SSRI at doses below $150 \mathrm{mg} /$ day, and like SNRI at doses above $150 \mathrm{mg} /$ day. Its efficacy was approved mainly in patients with PDN, but not in those with PHN (3). Venlafaxine extended-release is better tolerated than immediate-release the main side effects are gastrointestinal disturbances. However, increased blood pressure and clinically significant electrocardiography (ECG) changes are reported in 5\% of patients with PDN. Only high doses of venlafaxine (150 - $225 \mathrm{mg} /$ day) are effective. Clinicians discontinuing venlafaxine treatment should consider tapering the medication dose gradually because of its withdrawal syndrome (41). Venlafaxine does not bind to muscarinic -cholinergic, histaminic or alpha-adrenergic receptors responsible for the common adverse effects observed with TCAs (42). SSRIs and SNRIs may be considered only if the treatment with TCAs and anticonvulsants fails, or there are contraindications to these drugs (29).

\subsubsection{Anti-Epileptics}

Since 1940 and 50s anti-epileptics are used to manage pain and hydantoin derivatives such as phenytoin are used to treat trigeminal neuralgia $(43,44)$. Thereafter, carbamazepine was successful to treat trigeminal neuralgia. Enormous literature is available to support the role of antiepileptics in PHN, painful diabetic neuropathis, etc. Currently available anti-epileptics are carbamazepine, oxcarbazepine, gabapentin, lamotrigine, phenytoin, valproate and topiramate which show promising role in chronic pain. Mechanisms of action of these drugs are divergent and discussed in the subsequent sections. Adverse events are generally minimized by careful dose titrations and their common central nervous system (CNS) and hematological reactions are reported.

\subsubsection{Carbamazepine}

Analgesic activity of carbamazepine is documented in trigeminal neuralgia, PDN and PHN cases. It is approved by FDA to treat trigeminal neuralgia. It slows down the recovery rate of voltage gated sodium channels in a frequency dependent way, thereby unaffecting the normal nerve conduction process. Dosage ranges from 300 to $1000 \mathrm{mg} /$ day in divided doses (twice a day). According to a Cochrane review, NNT for carbamazepine was 1.7 in patients with PHN (45). Side effects include dizziness, drowsiness, balance difficulties, skin rash, thrombocytopenia, hepatic damage and rarely leukopenia (46).

\subsubsection{Oxcarbazepine}

Oxcarbazepine is effective on patients with trigeminal neuralgia, PDN and those with refractory to other antiepileptic drugs, such as carbamazepine and gabapentin (47). Oxcarbazepine 1200 and $1800 \mathrm{mg} /$ day are effective on patients with PDN (48). Side effect profile includes fatigue, weakness, erythematous rash and hyponatremia (4.3\%); hence sodium blood monitoring is advised.

\subsubsection{Lamotrigine}

Lamotrigine is effective in NP with HIV origin $(49,50)$, central post stroke pain (51) and in patients with spinal cord injury and incomplete lesions (52). Skin rash is the most frequent side effect of lamotrigine leading to its withdrawal. This can be minimized by keeping the starting dose as low as $25 \mathrm{mg} /$ day and increasing slowly every week to a maximum of $400 \mathrm{mg} /$ day. In one of the Cochrane review involving a total of 1511 participants with different types of NP, no positive outcome was documented by lamotrigine therapy (53).

Valproic acid: Use of valproic acid as a first line agent for NP is not convincing. Earlier studies showed that it may 
be effective on patients with PDN and PHN $(54,55)$. Its use in combination with glyceryl trinitrate spray is effective to manage diabetic neuropathy (56). NNT for valproic acid was 7 . More studies are necessary to provide convincing data to support the role in NP.

Topiramate: This is another antiepileptic drug studied only in diabetic neuropathic condition. No significant therapeutic efficacy of topiramate is reported in patients with PDN, even at the titrated doses 200 to $400 \mathrm{mg} /$ day. Weight loss and withdrawal effects are reported at higher doses (57).

\subsubsection{Gabapentin and Pregabalin}

These drugs have high affinity towards the $\alpha 2 \delta$ subunit of voltage gated calcium channels; thereby reduce the calcium influx into the neuron and subsequent neurotransmitter (substance-P, glutamate and norepinephrine) release (58). Both of these agents are effective for NP. However, only pregabalin is approved by FDA to manage both diabetic peripheral neuropathy and PHN, whereas gabapentin was approved for PHN (59). Their off-label use in post-operative pain (60) is only limited to reduce the dose of opioids and growing body of evidence suggests their use as perioperative rather than for acute pain (61). Gabapentin is ineffective in chemotherapy induced painful neuropathy. NNT for gabapentin is 6.4 and 4.3 in case of painful diabetic polyneuropathy and PHN, respectively (62). Efficacy of gabapentin and pregabalin was also documented in postoperative pain conditions (63).

Gabapentin exhibits saturable absorption that makes its pharmacokinetics less predictable. It is minimally protein bound $(<3 \%)$, and is excreted from the kidneys as an unchanged drug. Dosage adjustment should be done according to individual creatinine clearance in case of patients with renal impairment (64). Treatment should be initiated at low dose and slowly increased. Effective dosage for gabapentin ranges from 1800 to $3600 \mathrm{mg} /$ day (administered in three divided doses). Generally, two weeks are required to observe the effect, although several weeks are needed for titration. Dizziness, somnolence, peripheral edema, weight gain and dry mouth are the most common side effects (64). Pregabalin is as effective as gabapentin, however at much lower doses. The effective dose range for pregabalin is 150 to $600 \mathrm{mg} / \mathrm{day}$, but some clinicians recommend to start with $75 \mathrm{mg} /$ day at bed time to reduce the likelihood of early side effects, especially in the elderly (3). Furthermore, NNT for pregabalin is reported 4.5 and 4.2 for painful diabetic neuropathy and PHN, respectively (62). Besides, use of pregabalin is associated with increase in suicidal behavior and ideation, and patients taking this medication should be monitored for any abnormal changes in mood and behavior.

\subsubsection{Topical Lidocaine}

USFDA approved this drug to treat PHN. It relieves pain by acting directly on damaged pain fibers under the patch and reduces aberrant firing of sodium channels. But in recently conducted double blind RCT it was found that $29 \%$ - $80 \%$ of patients experienced sufficient pain relief with 5\% lidocaine patch. Apart from this, it protects against thermal and pinprick insults suggesting only partial block of $A \delta$ and $C$ fibers (65). Lidocaine patches are generally safe and lack systemic side effects. NNT for $5 \%$ lidocaine patch in patients with PHN is reported 4.4 (66). It should be used with caution in patients receiving antiarrhythmic drugs such as tocainide and mexiletine because of possible additive toxic effects. Its efficacy in PHN, post-stroke pain and complex regional pain syndrome (CRPS) is also documented (67). There are no studies available on pregnant females, but as it is excreted in human milk, caution should be exercised in case of nursing mothers. Up to 4 patches/day for a maximum of 12 hours within a 24-hour period may be used to cover the painful area.

\subsubsection{Opioids}

There have been controversial results for the efficacy of opioids in NP. However, studies of intermediate term showed significant protective effect of opioids over placebo to reduce NP(68). But recent trials with oxycodone controlled release formulation showed $(69,70)$ that strong opioids are superior to nortriptyline and naproxen in terms of pain relief in chronic noncancer pain. In another clinical trial, consisting of patients with diabetic neuropathy, NNT for controlled release oxycodone was 2.6 to achieve at least 50\% pain relief (71). Opioids are generally reserved for patients failed with first line regimen, for episodic discharges in sever chronic pain, for NP of cancer origin and for prompt relief of pain during titration of first line medications (25).

Common adverse effects include nausea, vomiting, sedation and constipation. Titrating gradually with low doses relieves nausea and sedation but constipation drives the attention for adjuvant bowel regimen. Long term therapy with opioids results in hypogonadism resulting in infertility in males and females, decreased libido, aggression and galactorrhea (72). Physical dependence is another problem with long term therapy of opioids and patients are instructed to taper the dosage gradually during the discontinuation of treatment (25). Opioid induced hyperalgesia is of growing concern in chronic therapy and the precise molecular mechanism in the relevant clinical settings is not clear yet. NMDA receptors become activated by opioids leading to influx of calcium thereby causing sensitization of nociceptive pathways (73). In addition, enhanced levels of pro-nociceptive peptides such as calcitonin gene 
related peptide (CGRP) and substance-P were found in DRG upon repeated morphine exposure (74). Treatment for opioid induced hyperalgesia includes reduction in the dose of opioid and supplementation with NMDA modulators.

\subsubsection{Methadone}

It is a synthetic opioid agonist with affinity for $\mu$-opioid receptors. It also has NMDA receptor antagonistic actions. Methadone has excellent oral and rectal absorption, high potency, low cost, with no known active metabolites which make it attractive for the therapy. But its use is limited by its remarkably long and unpredictable half-life (24 - 36 hours). Short term studies showed efficacy of methadone in $\mathrm{NP}(75,76)$, but long term safety is not yet established.

\subsubsection{Fentanyl}

It is a short acting opioid analgesic with greater permeability and efficacy (75 times) than that of morphine and higher selectivity for $\mu 1$-receptors. Efficacy of fentanyl patch in soft tissue cancer pain is documented. Its small molecular size makes it suitable to deliver via transdermal patch. Doses of 25, 50, 75 and $100 \mu \mathrm{g} /$ hour were effective but side effects were also observed in $72 \%$ of treated subjects (77). Severe diarrhea in the first 72 hours of fentanyl patch was also reported in three cases (78).

\subsubsection{Tramadol}

It is the only drug demonstrating week affinity for $\mu$-opioid receptors and also inhibits reuptake of monoamines. It is a centrally acting analgesic with both $(+)$ and $(-)$ enantiomers. The (+) tramadol stimulates presynaptic release of serotonin and also inhibits its reuptake, whereas (-) tramadol inhibits norepinephrine reuptake. According to a Cochrane review, the number of NNT for tramadol to get at least $50 \%$ pain relief was 3.8 over placebo (79). Starting dose should be of $50 \mathrm{mg}$ once daily (particularly in elder patients) and titrated as needed to up to $400 \mathrm{mg} /$ day. Risk of seizures is associated with higher doses and should be adjusted in patients with hepatic and renal impairment.

Other example of this category is tapentadol which has high NNT (10.2) with both positive and negative outcomes (38). It has agonistic action at mu-opioid receptors and also inhibits noradrenaline reuptake.

\subsubsection{Cannabinoids}

The cannabinoids are effective in various animal models of NP $(80,81)$. Discovery of endogenous ligands for the cannabinoid receptors boosted their research in the chronic pain conditions. A cannabinoid-based oromucosal spray (2.7 mg delta-9-tetrahydrocannabinol/2.5 mg cannabidiol) is effective in multiple sclerosis-associated pain. But the adverse effects include dizziness, dry mouth, sedation, fatigue, gastrointestinal effects and oral discomfort (82). Inhaled 9.4\% tetrahydrocannabinol at a dose of $25 \mathrm{mg}$ was effective on patients with post-traumatic and post-surgical neuropathic pain. It also improved the quality of sleep; but drug related dry eyes headache, burning sensation and cough were also reported (83). Long term studies on the safety of these cannabinoids are yet to come. Besides, prescribing smoked cannabis is restricted to resistant cases and caution should be taken in patients with cardiovascular disorders. Recently, preliminary guidelines also give knowledge about the use of smoked cannabis (84). Synthetic cannabinoid such as nabilone ( $1 \mathrm{mg} /$ day) decreased spasticity related pain without much of these adverse effects (85). Further, adjuvant effects of 10 and $20 \mathrm{mg}$ doses of dronabinol were also observed in patients with chronic pain who are under opioid therapy (86). Although no difference in pain suppression was observed between amitriptyline and nabilone, nabilone was better in improving the quality of sleep and is considered as an alternative to amitriptyline, but its long term safety profile should be assessed further (87).

Meanwhile, the results of a clinical trial on the efficiency of fatty acid amide hydrolase (FAAH) inhibitor, PF04457845, was unsuccessful in controlling osteoarthritic pain in spite of being effective in animal models of neuropathic pain (88). But combined administration of monoacylglycerol lipase (endocannabinoid catabolic enzyme) inhibitor in combination with NSAIDs was promising in animal models of neuropathic pain; however its clinical relevance should be established (89). A small study on 21 patients with different types of neuropathic pain showed that treatment with ajulemic acid (CT-3) was associated with reduced mechanical allodyania and overall pain score; CT-3 is agonist at both CB1 and CB2 receptors with partial affinity towards peroxisome proliferatoractivated receptor- $\gamma$ (PPAR- $\gamma$ ) and is devoid of central side effects $(90,91)$.

\subsubsection{N-Methyl-D-Aspartate Receptor Antagonists}

Ketamine and dextromethorphan are the two most studied NMDA receptor antagonists in NP. Dextromethorphan $400 \mathrm{mg} /$ day is effective on patients with PDN, but not in those with PHN. Recent trial of dextromethorphan in combination with quinidine had promising results in patients with PDN (92). In addition, ketamine administered by intravenous (93) and intranasal (94) routes showed efficacy in NP, but caused somnolence and dizziness. Although memantine has low side effect profile owing to its rapid blocking/unblocking kinetics at the NMDARs, it seems to exhibit only little or no effect on patients with PDN and PHN (95). In opium abusers, combination of ketamine 
and morphine was effective on postoperative painful condition but the side effect profile remained similar to that of opioids (96). Besides, preoperative administration of dextromethorphan reduced the pain intensity and opioid requirement in patients undergoing arthroscopic surgery (97). Present data are still conflicting about the efficacy of NMDA antagonists in NP. Therefore, studies consisting of agents that would reduce increased NMDA receptor activity without affecting their physiological function are yet to come.

\subsubsection{Alpha 2-Adrenoceptor Agonists}

Applying $0.1 \%$ clonidine gel topically on the feet reduced the level of pain in patients with PDN (98). Furthermore, clonidine along with opioid is more effective than clonidine alone to relieve pain in patients with NP(99). Tizanidine is another drug which belongs to this class, with a dose range of 6 to $36 \mathrm{mg} /$ day, and shows efficacy in patients with NP (100). Clinical studies supported its use to manage spasticity associated with multiple sclerosis (MS), acquired brain injury or spinal cord injury. Tizanidine is well tolerated, compared to clonidine, regarding the incidence of side effects, such as hypotension, bradycardia and sedation at antihyperalgesic doses, which are lower than that of clonidine. The $\alpha 2$-agonist dexmedetomidine, compared with clonidine, is a selective drug, which is well tolerated and has FDA approval for its short sedative and analgesic actions. It is used mainly in adjunction to local anesthetics owing to its ability to reduce onset, increased duration of sensory block, prolonged postoperative analgesia and reduction in the analgesic dose needed (101).

\subsubsection{Topical Capsaicin}

The efficacy of capsaicin cream (0.025\% - 0.075\%) in patients with PDN and PHN is well studied. Now, a high concentration (8\%), which is about 100 times greater than conventional creams of capsaicin, is approved in EU and USA for PHN and painful HIV associated neuropathy. It is an agonist of the transient receptor potential vanilloid1 (TRPV1) causing depolarization, action potential generation and transmission of pain signals. But on repeated application, axons expressing these receptors are desensitized thereby inhibiting pain transmission. Although depletion of substance-P is proposed as a mechanism of action of capsaicin in pain relief, it is suggested that defunctionalisation of nociceptors fibers is the key step involved. NNT for high dose of capsaicin (8\%) single patch to get more than 30\% pain relief was between 10 and 12 (102). In a Cochrane review performed by Derry et al., it was concluded that high concentration (8\%) of topical capsaicin relieved pain in a subset of population along with improvements in sleep, fatigue, depression and quality of life (102).

\subsubsection{Botulinum Toxin}

This is a neurotoxin with a protective role in spasticity, focal dystonia and chronic migraine pain. It has FDA approval for strabismus, focal dystonia, blepharospasm and upper limb spasticity indications. Mechanism of action proposed for its therapeutic effect is not clear but inhibition of release of neural substances and neurotransmitters thereby causing reduction of neurogenic inflammation is reported (103). Clinical trials on traumatic and diabetic neuropathic pain showed promising results with subcutaneous injections and importantly no systemic side effects were reported. Efficacy was reported after one week of administration and lasted for three weeks. Studies involving trigeminal neuralgia, spinal cord injury, complex regional pain syndrome and PHN also showed promising results with botulinum toxin treatment with minimal side effect profile and is well tolerated (104-108).

\subsubsection{Combination Therapy}

Combination pharmacotherapy of NP involving different combinations of opioid and TCAs, gabapentin/pregabalin, cholecystokinin blocker, gabapentin and nortriptyline, gabapentin and alphaliopic acid, fluphenazine and TCAs frequently resulted in some form of adverse effects on central nervous system such as sedation and depression, etc. Among these, gabapentin in combination with morphine (109) and gabapentin with nortriptyline resulted in more efficacious pain relief than either drugs given alone (110). Gabapentin in combination with oxycodone also showed better pain relief than these drugs alone, but had sleep disturbances as a side effect (111). Ketamine infusion in low doses along with oral gabapentin reduced the pain scores in patients with spinal cord injury and is well tolerated (112). However, delusions were reported with this combination. Other combination studies include morphine with amitriptyline, morphine with nortriptyline, duloxetine with methadone, amitriptyline with ketamine and carbamazepine, ketamine with calcitonin, and doxepin with capsaicin which proved unsuccessful in neuropathic pain treatment because of several reasons (111). Eisenberg et al. in their review clearly described the drug combinations for neuropathic pain treatment and the reasons behind their failure (111).

Delayed sensory blockade with no significant postoperative analgesic effects were obtained for the combination of magnesium with bupivacaine for spinal anesthesia in females undergoing cesarean section (113).

\subsection{Possible Future Therapies}

Selective knock down of sensory neuron specific PN3 but not NaN sodium channel gene expression with anti- 
sense oligo-deoxynucleotides in DRG neurons prevented the hyperalgesia and allodynia following nerve injury in rats (114). These sodium channel subtypes with their particular distribution to the peripheral somatosensory system are now considered as targets to develop novel analgesic drugs for NP.

Disrupting specific NMDAR phosphorylation sites or inhibiting tyrosine kinases ( $\mathrm{Src}$ ) and casein kinase 2 (CK2) may inhibit pathological NMDAR activity without blocking the physiological function of NMDARs (95).

Spinal glial cells were activated by damage to peripheral nerves and affected dorsal horn neurons via purinergic receptors $\left(\mathrm{P}_{2} \mathrm{X}_{\mathrm{Y}}\right)$, chemokines $\left(\mathrm{CX}_{3} \mathrm{CRs}\right)$, immune related molecules, release of glutamate, reactive oxygen species (ROS), adenosine tri phosphate (ATP), CGRP which lead to activation mitogen-activated protein kinases (MAPK) family (p38 MAPK/ERK). Consequently, the activated glia releases a variety of diffusible mediators including proinflammatory cytokines/chemokines such as interleukin (IL)-1, IL-6 and tumor necrosis factor (TNF)- $\alpha$. These proinflammatory mediators act on their respective receptors reinforcing the pain in the spinal cord. Further, activated microglia increases calcium signaling in astrocytes leading to an increase in neuronal hyperexcitability and pain transmission (115).

Rostral ventral medulla on-cell modulators (improgan) are effective against mechanical allodynia following unilateral spinal nerve ligation in rats (116). Further, inhibiting brain P450 epoxygenase activity abolishes the improgan antinociception; thus providing a future hope for newer non-opioid, non-cannabinoid analgesics acting through supra-spinal sites to inhibit NP.

Tetrahydrobiopterin $\left(\mathrm{BH}_{4}\right)$ levels elevated under nerve injury conditions (117). Sepiapterin reductase (SPR) is a terminal enzymatic reaction in the production of $\mathrm{BH} 4$. Inhibiting SPR allows the cells in liver and other peripheral sites to synthesize BH4 independent of SPR, through dihydrofolate reductase (DHFR). But, the lower expression of DHFR in CNS allows decreased levels of BH4 via inhibition of SPR. There is also another rate limiting step in the production of BH4 via GTP cyclohydrolase-1 (GCH-1) (117). Consequently, decreasing BH4 levels lead to induction of analgesia via the above mentioned pathways. Sulfasalazine is an FDA approved drug for its anti-inflammatory and immuno-modulatory actions in rheumatoid arthritis, which possesses SPR inhibiting actions. In diabetic neuropathy on rats with diabetes, sulfasalazine completely blocked the development of tactile allodynia implying the anti-nociceptive effects. Collectively, minimal side effect profile of sulfasalazine suggests the future development of SPR inhibitors for chronic pain treatment. Apart from these, Gilron et al. mentioned the list of newer drugs in phase II clinical trials (118).

\subsection{Agents Effective on Peripheral Diabetic Neuropathy}

Apart from insulin, thiazolidinediones and other antidiabetic agents are partially effective on patients with PDN. Inhibitors of aldose reductase, NADPH oxidase, advanced glycation end products, protein kinase $\mathrm{C}$ (PKC) and poly-ARP are now emerging as novel therapeutic options for PDN. Epalrestat is the only aldose reductase inhibitor approved in Japan, has greater efficacy and tolerability in improving PDN. The mRNA levels of $\gamma$-glutamylcysteine synthetase, an enzyme involved in reduced glutathione (GSH) synthesis, is dramatically increased by epalrestat contributing to its efficacy in patients with PDN (119).

PKC activation secondary to increased diacylglycerol levels in diabetes leads to altered expression of nitric oxide synthetase and vascular endothelial growth factor (VEGF) in endothelia cells causing PDN. Ruboxistaurin, a PKC- $\beta$ inhibitor is orally effective in preventing the visual loss in patients with diabetic retinopathy (120).

\section{Conclusions}

Due to lack of effective pain reliving agents for chronic pain such as NP, only insufficient treatment options are available at present. This, along with complex underlying pathophysiological mechanisms makes it challenging to provide adequate analgesia for patients with NP. It is further hoped that future development of newer drugs with adequate efficacy and free from adverse effects or at least with minimum side effect profile make their way to treat the patients with chronic pain of different etiologies.

\section{Acknowledgments}

The authors express their gratitude to the adhoc project sanctioned to Professor Anil Kumar by Indian council of medical research (ICMR), New Delhi, India.

\section{Footnotes}

Authors' Contribution: Study concept and design, Anil Kumar, Archana Bhatnagar, Raghavender Pottabathini; acquisition of data, Raghavender Pottabathini, Sukant Garg; analysis and interpretation of data, Raghavender Pottabathini, Sukant Garg; drafting of the manuscript, Anil Kumar, Archana Bhatnagar; critical revision of the manuscript for important intellectual content, Anil Kumar; administrative, technical and material support, Archana Bhatnagar, Sukant Garg, Varun Gupta; study supervision, Anil Kumar. 
Funding/Support: The current study received grant support from Indian Council of Medical Research and Raghavender Pottabathini is the SRF in this project.

\section{References}

1. Merskey H, Bogduk N. Classification of Chronic Pain. 2 ed. Seattle: IASP Press; 2012.

2. Jensen MP, Chodroff MJ, Dworkin RH. The impact of neuropathic pain on health-related quality of life: review and implications. Neurology. 2007;68(15):1178-82. doi: 10.1212/01.wnl.0000259085.61898.9e. [PubMed: 17420400].

3. Dworkin RH, O'Connor AB, Backonja M, Farrar JT, Finnerup NB, Jensen TS, et al. Pharmacologic management of neuropathic pain: evidence-based recommendations. Pain. 2007;132(3):237-51. doi: 10.1016/j.pain.2007.08.033. [PubMed: 17920770].

4. van Hecke O, Austin SK, Khan RA, Smith BH, Torrance N. Neuropathic pain in the general population: a systematic review of epidemiological studies. Pain. 2014;155(4):654-62. doi: 10.1016/j.pain.2013.11.013. [PubMed: 24291734].

5. Backonja M, Woolf CJ. Future directions in neuropathic pain therapy: closing the translational loop. Oncologist. 2010;15 Suppl 2:24-9. doi: 10.1634/theoncologist.2009-S502. [PubMed: 20489194].

6. Baron R. Mechanisms of disease: neuropathic pain-a clinical perspective. Nat Clin Pract Neurol. 2006;2(2):95-106. doi: 10.1038/ncpneuro0113. [PubMed: 16932531].

7. Baron R, Binder A, Wasner G. Neuropathic pain: diagnosis, pathophysiological mechanisms, and treatment. Lancet Neurol. 2010;9(8):807-19. doi: 10.1016/s1474-4422(10)70143-5.

8. Taylor BK. Spinal inhibitory neurotransmission in neuropathic pain. Curr Pain Headache Rep. 2009;13(3):208-14. [PubMed: 19457281].

9. Yowtak J, Lee KY, Kim HY, Wang J, Kim HK, Chung K, et al. Reactive oxygen species contribute to neuropathic pain by reducing spinal GABA release. Pain. 2011;152(4):844-52. doi: 10.1016/j.pain.2010.12.034. [PubMed: 21296500].

10. Kovelowski CJ, Ossipov MH, Sun H, Lai J, Malan TP, Porreca F. Supraspinal cholecystokinin may drive tonic descending facilitation mechanisms to maintain neuropathic pain in the rat. Pain. 2000;87(3):265-73. doi: 10.1016/s0304-3959(00)00290-6.

11. Hanlon KE, Herman DS, Agnes RS, Largent-Milnes TM, Kumarasinghe IR, Ma SW, et al. Novel peptide ligands with dual acting pharmacophores designed for the pathophysiology of neuropathic pain. Brain Res. 2011;1395:1-11. doi:10.1016/j.brainres.2011.04.024. [PubMed: 21550594].

12. Cohen SP, Mao J. Neuropathic pain: mechanisms and their clinical implications. BMJ. 2014;348:f7656. doi: 10.1136/bmj.f7656. [PubMed: 24500412].

13. Tontodonati M, Ursini T, Polilli E, Vadini F, Di Masi F, Volpone D, et al. Post-herpetic neuralgia. Int J Gen Med. 2012;5:861-71. doi: 10.2147/IJGM.S10371. [PubMed: 23109810].

14. Gupta R. Postherpetic Neuralgia-Pain Management: Essential Topics for Examinations. Berlin, Heidelberg: Springer; 2014. pp. 79-81.

15. Sansone RA, Sansone LA. Pain, pain, go away: antidepressants and pain management. Psychiatry (Edgmont). 2008;5(12):16-9. [PubMed: 19724772].

16. Gao Y, Ning G, Jia WP, Zhou ZG, Xu ZR, Liu ZM, et al. Duloxetine versus placebo in the treatment of patients with diabetic neuropathic pain in China. Chin Med J (Engl). 2010;123(22):3184-92. [PubMed: 21163113].

17. Barnet CS, Tse JY, Kohane DS. Site 1 sodium channel blockers prolong the duration of sciatic nerve blockade from tricyclic antidepressants. Pain. 2004;110(1-2):432-8. doi: 10.1016/j.pain.2004.04.027. [PubMed: 15275796].

18. Lavoie PA, Beauchamp G, Elie R. Tricyclic antidepressants inhibit voltage-dependent calcium channels and $\mathrm{Na}(+)-\mathrm{Ca} 2+$ ex- change in rat brain cortex synaptosomes. Can J Physiol Pharmacol. 1990;68(11):1414-8. [PubMed: 2285885].

19. Reynolds IJ, Miller RJ. Tricyclic antidepressants block N-methyl-Daspartate receptors: similarities to the action of zinc. Brit JClin Pharmaco. 1988;95(1):95-102. doi: 10.1111/j.1476-5381.1988.tb16552.x.

20. Shlay JC, Chaloner K, Max MB, Flaws B, Reichelderfer P, Wentworth $\mathrm{D}$, et al. Acupuncture and amitriptyline for pain due to HIV related peripheral neuropathy: a randomized controlled trial. Terry Beirn Community Programs for Clinical Research on AIDS. JAMA. 1998;280(18):1590-5. [PubMed: 9820261].

21. Berger A, Dukes E, Mercadante S, Oster G. Use of antiepileptics and tricyclic antidepressants in cancer patients with neuropathic pain. Eur J Cancer Care (Engl). 2006;15(2):138-45. doi: 10.1111/j.13652354.2005.00624.x. [PubMed: 16643261].

22. O'Connor AB, Dworkin RH. Treatment of neuropathic pain: an overview of recent guidelines. Am J Med. 2009;122(10 Suppl):S22-32. doi: 10.1016/j.amjmed.2009.04.007. [PubMed: 19801049].

23. Saarto T, Wiffen PJ, Saarto T. Antidepressants for neuropathic pain. Cochrane Database Syst Rev. 2007(4) doi: 10.1002/14651858.CD005454.pub2. [PubMed: 17943857].

24. Coluzzi F, Mattia C. Mechanism-based treatment in chronic neuropathic pain: the role of antidepressants. Curr Pharm Des. 2005;11(23):2945-60. [PubMed: 16178755].

25. Dworkin RH, O'Connor AB, Audette J, Baron R, Gourlay GK, Haanpaa $\mathrm{ML}$, et al. Recommendations for the pharmacological management of neuropathic pain: an overview and literature update. Mayo Clin Proc. 2010;85(3 Suppl):S3-14. doi: 10.4065/mcp.2009.0649. [PubMed: 20194146].

26. Jackson KC. Pharmacotherapy for neuropathic pain. Pain Pract. 2006;6(1):27-33. doi: 10.1111/j.1533-2500.2006.00055.x. [PubMed: 17309706].

27. Max MB, Lynch SA, Muir J, Shoaf SE, Smoller B, Dubner R. Effects of desipramine, amitriptyline, and fluoxetine on pain in diabetic neuropathy. $N$ Engl J Med. 1992;326(19):1250-6. doi: 10.1056/NEJM199205073261904. [PubMed: 1560801].

28. Otto M, Bach FW, Jensen TS, Brosen K, Sindrup SH. Escitalopram in painful polyneuropathy: a randomized, placebo-controlled, crossover trial. Pain. 2008;139(2):275-83. doi: 10.1016/j.pain.2008.04.012. [PubMed: 18547727].

29. Lee YC, Chen PP. A review of SSRIs and SNRIs in neuropathic pain. Expert Opin Pharmacother. 2010;11(17):2813-25. doi: 10.1517/14656566.2010.507192. [PubMed: 20642317].

30. Jung AC, Staiger T, Sullivan M. The efficacy of selective serotonin reuptake inhibitors for the management of chronic pain.J Gen Intern Med. 1997;12(6):384-9. [PubMed: 9192257].

31. Bomholt SF, Mikkelsen JD, Blackburn-Munro G. Antinociceptive effects of the antidepressants amitriptyline, duloxetine, mirtazapine and citalopram in animal models of acute, persistent and neuropathic pain. Neuropharmacology. 2005;48(2):252-63. doi: 10.1016/j.neuropharm.2004.09.012. [PubMed: 15695164].

32. Semenchuk MR, Sherman S, Davis B. Double-blind, randomized trial of bupropion SR for the treatment of neuropathic pain. Neurology. 2001;57(9):1583-8. [PubMed: 11706096].

33. Pedersen LH, Nielsen AN, Blackburn-Munro G. Anti-nociception is selectively enhanced by parallel inhibition of multiple subtypes of monoamine transporters in rat models of persistent and neuropathic pain. Psychopharmacology (Berl). 2005;182(4):551-61. doi: 10.1007/s00213-005-0120-6. [PubMed: 16133135].

34. Watson CP, Gilron I, Sawynok J, Lynch ME. Nontricyclic antidepressant analgesics and pain: are serotonin norepinephrine reuptake inhibitors (SNRIs) any better?. Pain. 2011;152(10):2206-10. doi: 10.1016/j.pain.2011.05.032. [PubMed: 21723037].

35. Iyengar S, Webster AA, Hemrick-Luecke SK, Xu JY, Simmons RM. Efficacy of duloxetine, a potent and balanced serotoninnorepinephrine reuptake inhibitor in persistent pain mod- 
els in rats. J Pharmacol Exp Ther. 2004;311(2):576-84. doi: 10.1124/jpet.104.070656. [PubMed:15254142].

36. Kajdasz DK, Iyengar S, Desaiah D, Backonja MM, Farrar JT, Fishbain DA, et al. Duloxetine for the management of diabetic peripheral neuropathic pain: evidence-based findings from post hoc analysis of three multicenter, randomized, double-blind, placebocontrolled, parallel-group studies. Clin Ther. 2007;29 Suppl:2536-46. doi:10.1016/j.clinthera.2007.12.002. [PubMed: 18164920].

37. Smith EM, Pang H, Cirrincione C, Fleishman S, Paskett ED, Ahles T, et al. Effect of duloxetine on pain, function, and quality of life among patients with chemotherapy-induced painful peripheral neuropathy: a randomized clinical trial. JAMA. 2013;309(13):1359-67. doi: 10.1001/jama.2013.2813. [PubMed: 23549581].

38. Finnerup NB, Attal N, Haroutounian S, McNicol E, Baron R, Dworkin $\mathrm{RH}$, et al. Pharmacotherapy for neuropathic pain in adults: a systematic review and meta-analysis. Lancet Neurol. 2015;14(2):162-73. doi: 10.1016/s1474-4422(14)70251-0.

39. Sindrup SH, Tuxen C, Gram LF, Grodum E, Skjold T, Brosen K, et al. Lack of effect of mianserin on the symptoms of diabetic neuropathy. Eur J Clin Pharmacol. 1992;43(3):251-5. [PubMed: 1425887].

40. Dharmshaktu P, Tayal V, Kalra BS. Efficacy of antidepressants as analgesics: a review. J Clin Pharmacol. 2012;52(1):6-17. doi: 10.1177/0091270010394852. [PubMed: 21415285].

41. Fava M, Mulroy R, Alpert J, Nierenberg AA, Rosenbaum JF. Emergence of adverse events following discontinuation of treatment with extended-release venlafaxine. Am JPsychiatry. 1997;154(12):17602. doi: 10.1176/ajp.154.12.1760. [PubMed: 9396960].

42. Sumpton JE, Moulin DE. Treatment of neuropathic pain with venlafaxine. Ann Pharmacother. 2001;35(5):557-9. [PubMed: 11346061].

43. Lemoyne J. [Essential facial neuralgia therapy with dimethyl-dithiohydantoin]. Concours Med. 1951;73(6):461-3. [PubMed:14812778].

44. Blom S. Trigeminal Neuralgia: Its Treatment with a New Anticonvulsant Drug (G-32883). Lancet. 1962;279(7234):839-40. doi: 10.1016/s0140-6736(62)91847-0.

45. Saarto T, Wiffen PJ. Antidepressants for neuropathic pain: a Cochrane review. J Neurol Neurosurg Psychiatry. 2010;81(12):1372-3. doi: 10.1136/jnnp.2008.144964. [PubMed: 20543189].

46. Backonja MM. Use of anticonvulsants for treatment of neuropathic pain. Neurology. 2002;59(5, Suppl 2):S14-7. doi: 10.1212/WNL.59.5_suppl_2.S14.

47. Carrazana E, Mikoshiba I. Rationale and Evidence for the Use of Oxcarbazepine in Neuropathic Pain. J Pain Symptom Manag. 2003;25(5):S31-5. doi: 10.1016/s0885-3924(03)00067-8.

48. Beydoun A, Shaibani A, Hopwood M, Wan Y. Oxcarbazepine in painful diabetic neuropathy: results of a dose-ranging study. Acta Neurol Scand. 2006;113(6):395-404. doi: 10.1111/j.16000404.2006.00631.x. [PubMed: 16674606].

49. Simpson DM, McArthur JC, Olney R, Clifford D, So Y, Ross D, et al. Lamotrigine for HIV-associated painful sensory neuropathies: a placebocontrolled trial. Neurology. 2003;60(9):1508-14. [PubMed: 12743240].

50. Silver M, Blum D, Grainger J, Hammer AE, Quessy S. Doubleblind, placebo-controlled trial of lamotrigine in combination with other medications for neuropathic pain. J Pain Symptom Manage. 2007;34(4):446-54. doi: 10.1016/j.jpainsymman.2006.12.015. [PubMed: 17662571].

51. Vestergaard K, Andersen G, Gottrup H, Kristensen BT, Jensen TS. Lamotrigine for central poststroke pain: a randomized controlled trial. Neurology. 2001;56(2):184-90. [PubMed:11160953].

52. Finnerup NB, Sindrup SH, Bach FW, Johannesen IL, Jensen TS. Lamotrigine in spinal cord injury pain: a randomized controlled trial. Pain. 2002;96(3):375-83. doi:10.1016/s0304-3959(01)00484-5.

53. Wiffen PJ, Derry S, Moore RA, Wiffen PJ. Lamotrigine for chronic neuropathic pain and fibromyalgia in adults. Cochrane Database Syst Rev. 2013;3(12):CD006044. doi: 10.1002/14651858.CD006044.pub4. [PubMed: 24297457].

54. Kochar DK, Rawat N, Agrawal RP, Vyas A, Beniwal R, Kochar SK, et al. Sodium valproate for painful diabetic neuropathy: a randomized double-blind placebo-controlled study. QJM. 2004;97(1):33-8. [PubMed: 14702509].

55. Kochar DK, Garg P, Bumb RA, Kochar SK, Mehta RD, Beniwal R, et al. Divalproex sodium in the management of post-herpetic neuralgia: a randomized double-blind placebo-controlled study. Qjm. 2004;98(1):29-34. doi:10.1093/qjmed/hci005.

56. Agrawal RP, Goswami J, Jain S, Kochar DK. Management of diabetic neuropathy by sodium valproate and glyceryl trinitrate spray: a prospective double-blind randomized placebocontrolled study. Diabetes Res Clin Pract. 2009;83(3):371-8. doi: 10.1016/j.diabres.2008.12.018. [PubMed: 19208440].

57. Wiffen PJ, Derry S, Lunn MPT, Moore RA, Derry S. Topiramate for neuropathic pain and fibromyalgia in adults. Cochrane Database Syst Rev. 2013(8):CD008314. doi: 10.1002/14651858.CD008314.pub2. [PubMed: 23996081]

58. Sills GJ. The mechanisms of action of gabapentin and pregabalin. Curr Opin Pharmacol. 2006;6(1):108-13. doi: 10.1016/j.coph.2005.11.003. [PubMed: 16376147].

59. Devi P, Madhu K, Ganapathy B, Sarma G, John L, Kulkarni C. Evaluation of efficacy and safety of gabapentin, duloxetine, and pregabalin in patients with painful diabetic peripheral neuropathy. Indian J Pharmacol. 2012;44(1):51-6. doi: 10.4103/0253-7613.91867. [PubMed: 22345870].

60. Dauri M, Faria S, Gatti A, Celidonio L, Carpenedo R, Sabato AF. Gabapentin and pregabalin for the acute post-operative pain management. A systematic-narrative review of the recent clinical evidences. Curr Drug Targets. 2009;10(8):716-33. [PubMed: 19702520].

61. Engelman E, Cateloy F. Efficacy and safety of perioperative pregabalin for post-operative pain: a meta-analysis of randomizedcontrolled trials. Acta Anaesthesiol Scand. 2011;55(8) doi:10.1111/j.13996576.2011.02471.x.

62. Moulin D, Boulanger A, Clark AJ, Clarke H, Dao T, Finley GA, et al. Pharmacological management of chronic neuropathic pain: revised consensus statement from the Canadian Pain Society. Pain Res Manag. 2014;19(6):328-35. [PubMed: 25479151].

63. Imani F, Rahimzadeh P. Gabapentinoids: gabapentin and pregabalin for postoperative pain management. Anesth Pain Med. 2012;2(2):52-3. doi: 10.5812/aapm.7743. [PubMed: 24223337].

64. Singh D, Kennedy DH. The use of gabapentin for the treatment of postherpetic neuralgia. Clin Ther. 2003;25(3):852-89. doi: 10.1016/s0149-2918(03)80111-x.

65. Krumova EK, Zeller M, Westermann A, Maier C. Lidocaine patch (5\%) produces a selective, but incomplete block of Adelta and C fibers. Pain. 2012;153(2):273-80. doi: 10.1016/j.pain.2011.08.020. [PubMed: 21995882].

66. Meier T, Wasner G, Faust M, Kuntzer T, Ochsner F, Hueppe M, et al. Efficacy of lidocaine patch $5 \%$ in the treatment of focal peripheral neuropathic pain syndromes: a randomized, double-blind, placebo-controlled study. Pain. 2003;106(1):151-8. doi:10.1016/s03043959(03)00317-8.

67. Golzari SEJ, Soleimanpour H, Mahmoodpoor A, Safari S, Ala A. Lidocaine and Pain Management in the Emergency Department: A Review Article. Anesth Pain Med. 2014;3(3) doi:10.5812/aapm.15444.

68. Eisenberg E, McNicol E, Carr DB. Opioids for neuropathic pain. Cochrane Database Syst Rev. 2006(3):CD006146. doi: 10.1002/14651858.CD006146. [PubMed:16856116].

69. Furlan AD, Sandoval JA, Mailis-Gagnon A, Tunks E. Opioids for chronic noncancer pain: a meta-analysis of effectiveness and side effects. CMAJ. 2006;174(11):1589-94. doi: 10.1503/cmaj.051528. [PubMed: 16717269].

70. Ong EC. Controlled-release oxycodone in the treatment of neuropathic pain of nonmalignant and malignant causes. Oncology. 2008;74 Suppl 1:72-5. doi: 10.1159/000143223. [PubMed: 18758202].

71. Watson PCN, Moulin D, Watt-Watson J, Gordon A, Eisenhoffer J. 
Controlled-release oxycodone relieves neuropathic pain: a randomized controlled trial in painful diabetic neuropathy. Pain. 2003;105(1):71-8. doi: 10.1016/s0304-3959(03)00160-x.

72. Ballantyne JC. Opioid analgesia: perspectives on right use and utility. Pain Physician. 2007;10(3):479-91. [PubMed: 17525783].

73. Lee M, Silverman SM, Hansen H, Patel VB, Manchikanti L. A comprehensive review of opioid-induced hyperalgesia. Pain Physician. 2011;14(2):145-61. [PubMed: 21412369].

74. Ossipov MH, Lai J, King T, Vanderah TW, Porreca F. Underlying mechanisms of pronociceptive consequences of prolonged morphine exposure. Biopolymers. 2005;80(2-3):319-24. doi: 10.1002/bip.20254. [PubMed: 15795927].

75. Morley JS, Bridson J, Nash TP, Miles JB, White S, Makin MK. Lowdose methadone has an analgesic effect in neuropathic pain: a double-blind randomized controlled crossover trial. Palliat Med. 2003;17(7):576-87. [PubMed: 14594148].

76. Gagnon B, Almahrezi A, Schreier G. Methadone in the treatment of neuropathic pain. Pain Res Manag. 2003;8(3):149-54. [PubMed: 14657982].

77. Hemati K, Zaman B, Hassani V, Imani F, Dariaie P. Efficacy of fentanyl transdermal patch in the treatment of chronic soft tissue cancer pain. Anesth Pain Med. 2015;5(1):22900. doi: 10.5812/aapm.22900. [PubMed: 25789240].

78. Hemati K. The Incidence of Severe Diarrhea with Transdermal Fentanyl Patch: An Uncommon Event. J Clin Diagn Res. 2015;9(6) doi: $10.7860 /$ jcdr/2015/13194.6024.

79. Duhmke RM, Cornblath DD, Hollingshead JRF, Dühmke RM. Tramadol for neuropathic pain. Cochrane Database Syst Rev. 2004(2) doi: 10.1002/14651858.CD003726.pub2. [PubMed:15106216].

80. Liang YC, Huang CC, Hsu KS. The synthetic cannabinoids attenuate allodynia and hyperalgesia in a rat model of trigeminal neuropathic pain. Neuropharmacology. 2007;53(1):169-77. doi: 10.1016/j.neuropharm.2007.04.019. [PubMed:17572451].

81. Vera G, Cabezos PA, Martin MI, Abalo R. Characterization of cannabinoid-induced relief of neuropathic pain in a rat model of cisplatin-induced neuropathy. Pharmacol Biochem Behav. 2013;105:205-12. doi: 10.1016/j.pbb.2013.02.008. [PubMed: 23454533]

82. Attal N, Cruccu G, Baron R, Haanpaa M, Hansson P, Jensen TS, et al. EFNS guidelines on the pharmacological treatment of neuropathic pain: 2010 revision. EurJ Neurol. 2010;17(9):1113-e88. doi: 10.1111/j.14681331.2010.02999.x. [PubMed: 20402746].

83. Ware MA, Wang T, Shapiro S, Robinson A, Ducruet T, Huynh T, et al. Smoked cannabis for chronic neuropathic pain: a randomized controlled trial. CMAJ. 2010;182(14):694-701. doi: 10.1503/cmaj.091414. [PubMed: 20805210].

84. Kahan M, Srivastava A, Spithoff S, Bromley L. Prescribing smoked cannabis for chronic noncancer pain: preliminary recommendations. Can Fam Physician. 2014;60(12):1083-90. [PubMed: 25500598].

85. Wissel J, Haydn T, Muller J, Brenneis C, Berger T, Poewe W, et al. Low dose treatment with the synthetic cannabinoid Nabilone significantly reduces spasticity-related pain : a double-blind placebocontrolled cross-over trial. J Neurol. 2006;253(10):1337-41. doi: 10.1007/s00415-006-0218-8. [PubMed: 16988792].

86. Narang S, Gibson D, Wasan AD, Ross EL, Michna E, Nedeljkovic SS, et al. Efficacy of dronabinol as an adjuvant treatment for chronic pain patients on opioid therapy. I Pain. 2008;9(3):254-64. doi: 10.1016/j.jpain.2007.10.018. [PubMed: 18088560].

87. Ware MA, Fitzcharles MA, Joseph L, Shir Y. The effects of nabilone on sleep in fibromyalgia: results of a randomized controlled trial. Anesth Analg. 2010;110(2):604-10. doi: 10.1213/ANE.0b013e3181c76f70. [PubMed: 20007734].

88. Huggins JP, Smart TS, Langman S, Taylor L, Young T. An efficient randomised, placebo-controlled clinical trial with the irreversible fatty acid amide hydrolase-1 inhibitor PF-04457845, which modulates endocannabinoids but fails to induce effective analgesia in patients with pain due to osteoarthritis of the knee. Pain. 2012;153(9):1837-
46. doi: 10.1016/j.pain.2012.04.020. [PubMed: 22727500]

89. Crowe MS, Leishman E, Banks ML, Gujjar R, Mahadevan A, Bradshaw $\mathrm{HB}$, et al. Combined inhibition of monoacylglycerol lipase and cyclooxygenases synergistically reduces neuropathic pain in mice. Br J Pharmacol. 2015;172(7):1700-12. doi: 10.1111/bph.13012. [PubMed 25393148].

90. Rahn EJ, Hohmann AG. Cannabinoids as pharmacotherapies for neuropathic pain: from the bench to the bedside. Neurotherapeutics. 2009;6(4):713-37. doi: 10.1016/j.nurt.2009.08.002. [PubMed 19789075].

91. Karst M, Salim K, Burstein S, Conrad I, Hoy L, Schneider U. Analgesic effect of the synthetic cannabinoid CT-3 on chronic neuropathic pain: a randomized controlled trial. JAMA. 2003;290(13):1757-62. doi: 10.1001/jama.290.13.1757. [PubMed: 14519710].

92. Shaibani AI, Pope LE, Thisted R, Hepner A. Efficacy and safety of dextromethorphan/quinidine at two dosage levels for diabetic neuropathic pain: a double-blind, placebo-controlled, multicenter study.Pain Med. 2012;13(2):243-54. doi:10.1111/j.1526-4637.2011.01316.x. [PubMed: 22314263].

93. Kvarnstrom A, Karlsten R, Quiding H, Emanuelsson BM, Gordh T The effectiveness of intravenous ketamine and lidocaine on peripheral neuropathic pain. Acta Anaesthesiol Scand. 2003;47(7):868-77. [PubMed: 12859309].

94. Huge V, Lauchart $M$, Magerl W, Schelling G, Beyer A, Thieme $\mathrm{D}$, et al. Effects of low-dose intranasal (S)-ketamine in patients with neuropathic pain. Eur J Pain. 2010;14(4):387-94. doi: 10.1016/j.ejpain.2009.08.002. [PubMed: 19733106].

95. Zhou HY, Chen SR, Pan HL. TargetingN-methyl-D-aspartate receptors for treatment of neuropathic pain. Rev Clin Pharmacol. 2014;4(3):379-88. doi:10.1586/ecp.11.17.

96. Dahi-Taleghani M, Fazli B, Ghasemi M, Vosoughian M, Dabbagh A. Effect of Intravenous Patient Controlled Ketamine Analgesiaon Postoperative Pain in Opium Abusers. Anesth Pain Med. 2014;3(3) doi 10.5812/aapm.14129.

97. Entezary SR, Farshadpour S, Alebouyeh MR, Imani F, Emami Meybodi MK, Yaribeygi H. Effects of preoperative use of oral dextromethorphan on postoperative need for analgesics in patients with knee arthroscopy. Anesth Pain Med. 2014;4(1):11187. doi:10.5812/aapm.11187. [PubMed: 24660143].

98. Campbell CM, Kipnes MS, Stouch BC, Brady KL, Kelly M, Schmidt WK, et al. Randomized control trial of topical clonidine for treat ment of painful diabetic neuropathy. Pain. 2012;153(9):1815-23. doi: 10.1016/j.pain.2012.04.014. [PubMed: 22683276].

99. Ackerman LL, Follett KA, Rosenquist RW. Long-term outcomes during treatment of chronic pain with intrathecal clonidine or clonidine/opioid combinations. J Pain Symptom Manage. 2003;26(1):66877. doi: 10.1016/s0885-3924(03)00144-1.

100. Semenchuk MR, Sherman S. Effectiveness of tizanidine in neuropathic pain: an open-label study. J Pain. 2000;1(4):285-92. doi 10.1054/jpai.2000.9435. [PubMed: 14622612].

101. Solanki SL, Goyal VK. Neuraxial dexmedetomidine: wonder drug or simply harmful. Anesth Pain Med. 2015;5(2):22651. doi 10.5812/aapm.22651. [PubMed: 25866711].

102. Derry S, Rice ASC, Cole P, Tan T, Moore RA. Topical capsaicin (high concentration) for chronic neuropathic pain in adults. Cochrane Database Syst Rev. 2013(2) doi: 10.1002/14651858.CD007393.pub3. [PubMed: 23450576].

103. Intiso D, Basciani $M$, Santamato $A$, Intiso $M$, Di Rienzo F. Botulinum Toxin Type A for the Treatment of Neuropathic Pain in NeuroRehabilitation. Toxins (Basel). 2015;7(7):2454-80. doi: 10.3390/toxins7072454. [PubMed: 26134256].

104. Yoon SH, Merrill RL, Choi JH, Kim ST. Use of botulinum toxin type A injection for neuropathic pain after trigeminal nerve injury. Pain Med. 2010;11(4):630-2. doi:10.1111/j.1526-4637.2010.00801.x. [PubMed: 20210871]. 
105. Kharkar S, Ambady P, Venkatesh Y, Schwartzman RJ. Intramuscular botulinum toxin in complex regional pain syndrome: case series and literature review.Pain Physician. 2011;14(5):419-24. [PubMed: 21927045].

106. Apalla Z, Sotiriou E, Lallas A, Lazaridou E, Ioannides D. Botulinum toxin A in postherpetic neuralgia: a parallel, randomized, double-blind, single-dose, placebo-controlled trial. Clin J Pain. 2013;29(10):857-64. doi: 10.1097/AJP.ob013e31827a72d2. [PubMed: 23370074].

107. Ghasemi M, Ansari M, Basiri K, Shaigannejad V. The effects of intradermal botulinum toxin type a injections on pain symptoms of patients with diabetic neuropathy. J Res Med Sci. 2014;19(2):106-11. [PubMed: 24778662].

108. Han ZA, Song DH, Chung ME. Effect of subcutaneous injection of botulinum toxin A on spinal cord injury-associated neuropathic pain. Spinal Cord. 2014;52 Suppl 1:S5-6. doi: 10.1038/sc.2014.43. [PubMed: 24902645].

109. Chaparro LE, Wiffen PJ, Moore RA, Gilron I. Combination pharmacotherapy for the treatment of neuropathic pain in adults. Cochrane Database Syst Rev. 2012;11(7):CD008943. doi: 10.1002/14651858.CD008943.pub2. [PubMed: 22786518].

110. Gilron I, Bailey JM, Tu D, Holden RR, Jackson AC, Houlden RL. Nortriptyline and gabapentin, alone and in combination for neuropathic pain: a double-blind, randomised controlled crossover trial. Lancet. 2009;374(9697):1252-61. doi: 10.1016/s0140-6736(09)61081-3.

111. Eisenberg E, Suzan E. Drug combinations in the treatment of neuropathic pain. Curr Pain Headache Rep. 2014;18(12):463. doi: 10.1007/s11916-014-0463-y. [PubMed: 25298046].

112. Amr YM. Multi-day low dose ketamine infusion as adjuvant to oral gabapentin in spinal cord injury related chronic pain: a prospective, randomized, double blind trial. Pain Physician. 2010;13(3):2459. [PubMed: 20495588].
113. Banihashem N, Hasannasab B, Esmaeili A, Hasannasab B. Addition of Intrathecal Magnesium Sulfate to Bupivacaine for Spinal Anesthesia in Cesarean Section. Anesth Pain Med. 2015;5(3) doi: 10.5812/aapm.5(3)2015.22798.

114. Porreca F, Lai J, Bian D, Wegert S, Ossipov MH, Eglen RM, et al. A comparison of the potential role of the tetrodotoxin-insensitive sodium channels, PN3/SNS and NaN/SNS2, in rat models of chronic pain. Proc Natl Acad Sci U S A. 1999;96(14):7640-4. [PubMed: 10393873].

115. Palygin O, Lalo U, Verkhratsky A, Pankratov Y. Ionotropic NMDA and $\mathrm{P} 2 \mathrm{X} 1 / 5$ receptors mediate synaptically induced $\mathrm{Ca} 2+$ signalling in cortical astrocytes. Cell Calcium. 2010;48(4):225-31. doi: 10.1016/j.ceca.2010.09.004. [PubMed: 20926134].

116. Albrecht PJ, Nalwalk JW, Hough LB. Efficacy of improgan, a nonopioid analgesic, in neuropathic pain. Brain Res. 2011;1424:32-7. doi: 10.1016/j.brainres.2011.10.002. [PubMed: 22015352].

117. Costigan M, Latremoliere A, Woolf CJ. Analgesia by inhibiting tetrahydrobiopterin synthesis. Curr Opin Pharmacol. 2012;12(1):92-9. doi:10.1016/j.coph.2011.10.019. [PubMed: 22178186].

118. Gilron I, Dickenson AH. Emerging drugs for neuropathic pain. Expert Opin Emerg Drugs. 2014;19(3):329-41. doi: 10.1517/14728214.2014.915025. [PubMed: 24793304].

119. Sato K, Yama K, Murao Y, Tatsunami R, Tampo Y. Epalrestat increases intracellular glutathione levels in Schwann cells through transcription regulation. Redox Biol. 2013;2:15-21. doi: 10.1016/j.redox.2013.11.003. [PubMed: 24363998].

120. Aiello LP, Vignati L, Sheetz MJ, Zhi X, Girach A, Davis MD, et al. Oral protein kinase c beta inhibition using ruboxistaurin: efficacy, safety, and causes of vision loss among 813 patients (1,392 eyes) with diabetic retinopathy in the Protein Kinase $C$ beta InhibitorDiabetic Retinopathy Study and the Protein Kinase $C$ beta InhibitorDiabetic Retinopathy Study 2. Retina. 2011;31(10):2084-94. doi: 10.1097/IAE.ob013e3182111669. [PubMed: 21862954]. 